\title{
Hot Extrusion of Ceramics
}

\author{
Xin $\mathrm{Wu}^{\star}$ and I-Wei Chen ${ }^{\star}$ \\ Department of Materials Science and Engineering, University of Michigan, \\ Ann Arbor, Michigan 48109-2136
}

Two dense ceramics, $\mathrm{Bi}_{2} \mathrm{Sr}_{2} \mathrm{CaCu}_{2} \mathrm{O}_{8+X}$ and 2Y-TZP: $10 \mathrm{wt} \% \mathrm{Al}_{2} \mathrm{O}_{3}$, were hot-extruded through conical dies under a wide range of conditions. Extrusion of $\mathrm{Bi}_{2} \mathrm{Sr}_{2} \mathrm{Ca}$ $\mathrm{Cu}_{2} \mathrm{O}_{8+X}$ was performed at $775^{\circ}$ to $825^{\circ} \mathrm{C}$ and speeds of 0.0005 to $0.2 \mathrm{~mm} / \mathrm{s}$, with the die semi-angles from $30^{\circ}$ to $60^{\circ}$ and extrusion ratios from 4 to 9 . Extrusion of 2Y-TZP:10 wt $\% \mathrm{Al}_{2} \mathrm{O}_{3}$ was performed at $1650^{\circ} \mathrm{C}$ and $0.017 \mathrm{~mm} / \mathrm{s}$. During hot extrusion of $\mathrm{Bi}_{2} \mathrm{Sr}_{2} \mathrm{CaCu}_{2} \mathrm{O}_{8+X}$, a strong texture was developed with the basal plane aligned along the extrusion direction, whereas the zirconia/alumina composite underwent grain growth which resulted in strain hardening. A simple analytical extrusion model for strain-rate-sensitive materials has been developed using a combined slab method and upper-bound method and a power-law material flow equation. The model predictions are in good agreement with the experimental results and they further serve to delineate the limitation of the extrusion technique for ceramic applications. [Key words: extrusion, superconductors, zirconia, texture, creep.]

\section{Introduction}

$\mathbf{E}$ XTRUSION of polycrystalline ceramics has recently become a subject of considerable interest. Since the discovery of high- $T_{\mathrm{c}}$ superconducting oxides, numerous attempts have been made to use extrusion (or the similar wire drawing process) to manufacture highly textured wires. ${ }^{1-13}$ Such a texture is generally beneficial for the current-carrying capability of the high- $T_{\mathrm{c}}$ superconductors. In addition, fine-grained tetragonal zirconia polycrystals (TZP) have also been extruded into rods, ${ }^{14,15}$ although the utility of hot extrusion of this material is less obvious as no physical property has yet been found that benefits from the extrusion process.

Extrusion of ceramics is quite different from extrusion of metals. Ceramics have poorer ductility and higher flow stresses than metals, so the extrusion has to be performed under a much higher temperature and slower speed in order to reduce the flow stress and avoid fracture. Under such deformation conditions material flow stress is rate sensitive, and probably grain size sensitive also. In addition, hightemperature extrusion calls for tooling materials with an even higher strength at the extrusion temperature than the ceramics being extruded. Since choices of such tooling materials are very limited, extrusion may have to be performed under a constant upper limit load instead of a constant speed.

To further explore the possibility of hot extrusion of dense ceramics, a systematic theoretical and experimental study has been performed in the hot extrusion of two ceramics, $\mathrm{Bi}_{2} \mathrm{Sr}_{2} \mathrm{CaCu}_{2} \mathrm{O}_{8+X}$, a high- $T_{\mathrm{c}}$ superconducting ceramic, and 2Y-TZP:10 wt\% $\mathrm{Al}_{2} \mathrm{O}_{3}$ composite (Y10A), a fine-grained

F. Lange-contributing editor

Manuscript No. 198064. Received

Supported by the U.S. Department of Energy (BES) under Grant No. DEFG02-87ER45302.

* Member, American Ceramic Society. transformation-toughened ceramic. $\mathrm{Bi}_{2} \mathrm{Sr}_{2} \mathrm{CaCu}_{2} \mathrm{O}_{8+X}$ was chosen because, in our preliminary deformation study, ${ }^{2}$ it was found to form a useful deformation texture similar to that in $\mathrm{YBa}_{2} \mathrm{Cu}_{3} \mathrm{O}_{6.5+x}$, and it remained superconducting after hot deformation without any further heat treatment. In addition, the temperature required for extruding it was well within the upper limit where high-strength tungsten carbide tooling could be utilized. Therefore, it was considered to be a good model material for ceramics extrusion study. 2Y-TZP: 10 wt $\% \mathrm{Al}_{2} \mathrm{O}_{3}$ composite was chosen because fine-grained 2Y-TZP is known to have excellent superplasticity, and with the addition of 10 wt $\% \mathrm{Al}_{2} \mathrm{O}_{3}$ as a second phase, grain growth could be further suppressed. ${ }^{16}$ By using these two different materials over a sufficiently broad range of extrusion speeds, extrusion ratios, die angles, and temperatures, the representative extrusion behaviors could be thoroughly explored.

\section{Extrusion Mechanics}

Since most existing extrusion models are applicable to rate-independent materials, ${ }^{17-20}$ an extension of the classical extrusion analysis for rate-sensitive materials is needed. This analysis is given elsewhere using a combined slab method and upper-bound method. ${ }^{21}$ The main results are summarized below. Essentially, the extrusion ram pressure $P$ is determined by the material flow stress and the die geometry, which involves the extrusion ratio and the die angle. The former may vary with time because of microstructural changing taking place in extrusion. In addition, the actual pressure is affected by the friction between the billet and the container. This latter factor is also time-dependent since the length of the billet changes.

The first factor on flow stress is expressed by $Y^{*}$, which is a reference flow stress corresponding to a reference strain rate $\dot{\varepsilon}^{*}=V_{\mathrm{i}} / D_{\mathrm{i}}$,

$$
Y^{*}=k \dot{\varepsilon}^{* m}=k\left(\frac{V_{\mathrm{i}}}{D_{\mathrm{i}}}\right)^{m}
$$

where $V_{\mathrm{i}}$ and $D_{\mathrm{i}}$ are the inlet velocity and diameter. Using the standard notation for constitutive equation of flow stress, we can write $k=k_{0} \exp (m Q / R T)\left(d / d_{0}\right)^{m p}$, where $k_{0}, m, Q$, and $p$ are material constants referring to strain rate sensitivity, activation energy, and the grain size exponent, respectively, and $d$ and $d_{0}$ are the current and initial grain size, respectively. The effect of temperature and extrusion speed on the extrusion load is therefore determined by the temperature and strain rate dependence of the material.

The second factor on die geometry is expressed by $F_{\mathrm{g}}$, which is the extrusion pressure at the die inlet normalized by flow stress. It is determined by the die angle $\alpha$ and extrusion ratio $R(R=$ inlet area/outlet area) due to the ideal plastic work for the cross-sectional area reduction ( $R$-dependent), the die friction ( $\alpha$-dependent), and the redundant work due to velocity discontinuities at both the inlet and outlet ( $\alpha$ dependent). Taking into account the strain rate effect within 
the deformation zone, $F_{\mathrm{g}}$ can be written as

$$
\begin{aligned}
F_{\mathrm{g}}=(4 \tan \alpha)^{m} & \left\{\left(\frac{1+B}{B+1.5 m}\right)\left(R^{B+1.5 m}-1\right)+\frac{\tan \alpha}{3}\right. \\
& \left.\times\left(1+R^{1.5 m}\right)\right\}
\end{aligned}
$$

where $B=\mu / \tan \alpha$, with $\mu$ as the coulomb friction coefficient. The product of $F_{\mathrm{g}}$ and $Y^{*}$ is then the pressure (or extrusion stress $\sigma_{\mathrm{i}}$ ) required at the inlet to extrude material.

The third factor on billet-container friction is expressed by $F_{L}$, which is a function of the remaining billet length $L$,

$$
F_{L}=\exp \left(4 \mu L / D_{\mathrm{i}}\right)
$$

This factor decreases with length $L$ or time $t$. The product of $F_{L}, F_{\mathrm{g}}$, and $Y^{*}$ is then the pressure required on the ram to push the billet though the die.

Lastly, if microstructural coarsening occurs during extrusion, its effect can be expressed by $F_{\mathrm{d}}$, which accounts for the static grain growth of the billet,

$$
F_{\mathrm{d}}=(1+a t)^{m p / q}
$$

where $a$ and $q$ are given by the static growth law $d=$ $d_{0}(1+a t)^{1 / q}$. The product of $F$ and $Y^{*}$ is then the actual reference flow stress at time $t$. Likewise, the pressures $\sigma_{\mathrm{i}}$ and $P$ above need to be corrected by the same factor $F_{\mathrm{d}}$.

This model considers the effects of both extrusion processing parameters and material parameters. In addition, because of the contribution of the time-dependent factors $F_{\mathrm{d}}$ and $F_{L}$, the static extrusion condition, represented by a constant pressure-constant extrusion speed relation, is never achievable. In the following, we will find that for the two materials studied, deformation of $\mathrm{Bi}_{2} \mathrm{Sr}_{2} \mathrm{CaCu}_{2} \mathrm{O}_{8+X}$ is presumably controlled by dislocation creep (as evident by the texture formation) and thus is grain size independent, so that factor $F_{\mathrm{d}}$ is unity and factor $F_{L}$ dominates the kinetics of the extrusion. On the other hand, the deformation of the fine-grained zirconia composite is controlled by diffusional creep and is highly grain size dependent, so that factor $F_{\mathrm{d}}$ is increasing with time and may dominate the extrusion kinetics. Our experimental investigation described below will be analyzed using the above model.

\section{Experimental Procedure}

\section{(I) Material Preparation}

For preparing $\mathrm{Bi}_{2} \mathrm{Sr}_{2} \mathrm{CaCu}_{2} \mathrm{O}_{8+\chi}$, powders of $\mathrm{Bi}_{2} \mathrm{O}_{3}, \mathrm{SrCO}_{3}$, $\mathrm{CaCO}_{3}$, and $\mathrm{CuO}$, with molar ratios of $\mathrm{Bi}: \mathrm{Sr}: \mathrm{Ca}: \mathrm{Cu}$ being $2: 2: 1: 2$, were mixed and dissolved in nitric acid. The solution was then evaporated to dryness. The calcination was performed at $850^{\circ} \mathrm{C}$ for $24 \mathrm{~h}$ in air, followed by grinding and milling. Such a calcination-milling cycle was repeated three times for chemical homogenization. The resultant powder was found to contain primarily a $\mathrm{Bi}_{2} \mathrm{Sr}_{2} \mathrm{CaCu}_{2} \mathrm{O}_{8+X}$ phase and a few percent of Ca-rich phase.

The Y10A powder was prepared by mixing the powder of 2Y-TZP and $\mathrm{Al}_{2} \mathrm{O}_{3}$ (in a 9:1 weight ratio). The powder mixture was attrition milled in methanol for $2 \mathrm{~h}$, followed by drying.

The extrusion billets were made by hot-pressing in the same device and environment as that for extrusion. This will be described in the next section.

\section{(2) Hot-Pressing and Extrusion}

For extrusion of $\mathrm{Bi}_{2} \mathrm{Sr}_{2} \mathrm{CaCu}_{2} \mathrm{O}_{8+X}$, the container and dies were made of tungsten carbide, which can withstand extrusion pressures of up to $200 \mathrm{MPa}$ at extrusion temperatures of $775^{\circ}$ to $825^{\circ} \mathrm{C}$ in argon. Conical dies with an inlet diameter of $10 \mathrm{~mm}$ and extrusion ratios of $4,6.25$, and 9 (defined as the ratio of inlet area to outlet area) were used, all at a die semiangle of $40^{\circ}$. Extrusion at different die semi-angles of $30^{\circ}$, $40^{\circ}, 50^{\circ}$, and $60^{\circ}$ were also investigated, all at an extrusion ratio of 4 . Temperatures were measured by thermocouple and controlled by a temperature controller to within $1^{\circ} \mathrm{C}$ of the set value throughout the test. They were also checked by an additional thermocouple or by an optical pyrometer to ensure that the systematic error was within $5^{\circ} \mathrm{C}$.

The extrusion ram movement was activated by a closedloop controlled servo-hydraulic mechanical testing system with a displacement resolution of $3 \mu \mathrm{m}$. Extrusion was performed under displacement control mode. Load and displacement were measured by a load cell and a linear voltage differential transformer (LVDT), and were recorded by a computer. Ram speeds from 0.0005 to $0.2 \mathrm{~mm} / \mathrm{s}$ were used, giving extrusion speeds at the outlet from 0.002 to $0.8 \mathrm{~mm} / \mathrm{s}$, depending on the extrusion ratio.

In a typical run, powder of $\mathrm{Bi}_{2} \mathrm{Sr}_{2} \mathrm{CaCu}_{2} \mathrm{O}_{8+X}$ was directly charged into the extrusion container and hot-pressed between the extrusion piston and a plugged tungsten carbide die. This was performed under a constant pressure of $50 \mathrm{MPa}$ and at $800^{\circ} \mathrm{C}$ in argon for $30 \mathrm{~min}$ to reach better than $98 \%$ of the theoretical density. The resulting cylindrical billets were $10 \mathrm{~mm}$ in diameter and about $10 \mathrm{~mm}$ in length. After the die was unplugged, the ram was advanced at a constant speed for the remainder of the run to achieve extrusion. In order to obtain the relationship between extrusion load and speed, the ram speed was abruptly changed after certain distances and this was repeated several times in a run. Extrusion was terminated when the piston reached the position of $0.5 \mathrm{~mm}$ ahead of the die inlet.

To reduce friction and chemical reaction between the carbide dies and the billet, several jacketing materials were used. Silver, copper, and graphite foils were all found satisfactory for the lubrication purpose, although silver had a better chemical stability. In the extrusion modeling, only data obtained with a double-layer jacketing (a graphite outer foil and a silver inner foil, both $0.05 \mathrm{~mm}$ in thickness) were used.

For Y10A, the operation procedures for hot-pressing and extrusion were basically the same as that for $\mathrm{Bi}_{2} \mathrm{Sr}_{2} \mathrm{CaCu}_{2} \mathrm{O}_{8+\chi}$. However, the container and the extrusion dies were made of graphite instead of WC in order to withstand much higher extrusion temperatures. The billets were made by hot-pressing Y10A powder under $20 \mathrm{MPa}$ at $1420^{\circ} \mathrm{C}$ for $20 \mathrm{~min}$ in nitrogen, with the same operation procedure as for $\mathrm{Bi}_{2} \mathrm{Sr}_{2} \mathrm{CaCu}_{2} \mathrm{O}_{8+x}$. Extrusion was performed under $32-\mathrm{MPa}$ ram pressure (in the load control mode), at $1650^{\circ} \mathrm{C}$ in nitrogen, with die angles of $30^{\circ}, 45^{\circ}, 60^{\circ}$, and with an extrusion ratio of 4 . Only graphite foil was used for lubrication. Compared to the ones used by Kellet et al. for $3 \mathrm{Y}-\mathrm{TZP},{ }^{15}$ these conditions cover more die angles but are restricted to one extrusion ratio. The extrusion is faster in speed but carried out at a higher temperature.

\section{Results and Analysis}

\section{(1) Texture in Extruded $\mathrm{Bi}_{2}(\mathrm{Sr}, \mathrm{Ca})_{3} \mathrm{CuO}_{8+X}$}

$\mathrm{A} \mathrm{Bi}_{2} \mathrm{Sr}_{2} \mathrm{CaCu}_{2} \mathrm{O}_{8+X}$ rod extruded at $800^{\circ} \mathrm{C}$ and $0.01 \mathrm{~mm} / \mathrm{s}$ is shown in Fig. 1(a). Microstructural examinations revealed that extruded rods were dense and had elongated grains along the extrusion direction, as seen in Figs. 1(b) and (c). Strong crystalline textures were detected both before and after extrusion, but their crystalline orientations were different. Before extrusion, the hot-pressed billet had a preferred orientation with the basal plane $\{00 l\}$ aligned perpendicular to the pressing direction, as shown in Fig. 2 (top). After extrusion, the diffraction intensity of all basal $\{00 l\}$ planes is greatly reduced on the section normal to the extrusion direction, but is greatly enhanced on the section along the extrusion direction, as shown in Fig. 2 (bottom), indicating that the basal planes were preferentially aligned along the extrusion direction. Since the hot-pressing direction and the extrusion direction are the same with respect to the extruded rod, a $90^{\circ}$ rotation of the preferred orientation was experienced during extrusion. 


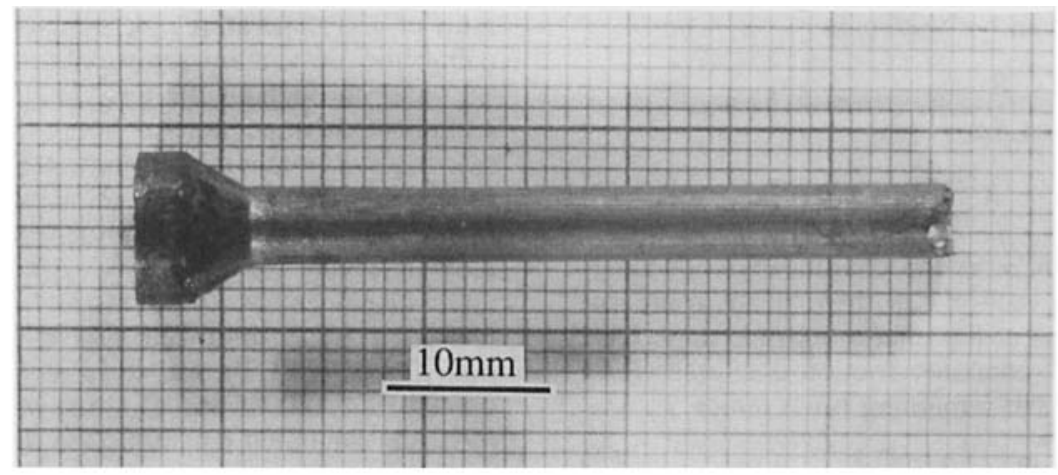

(a)

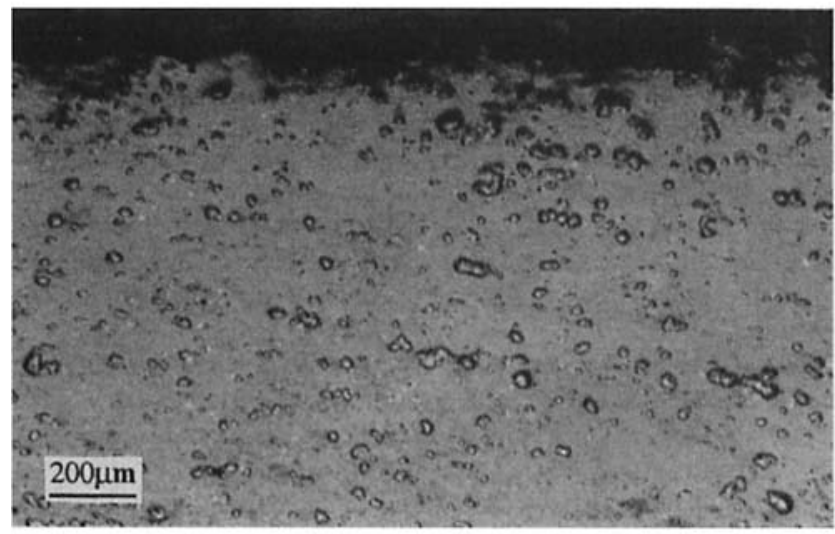

(b)

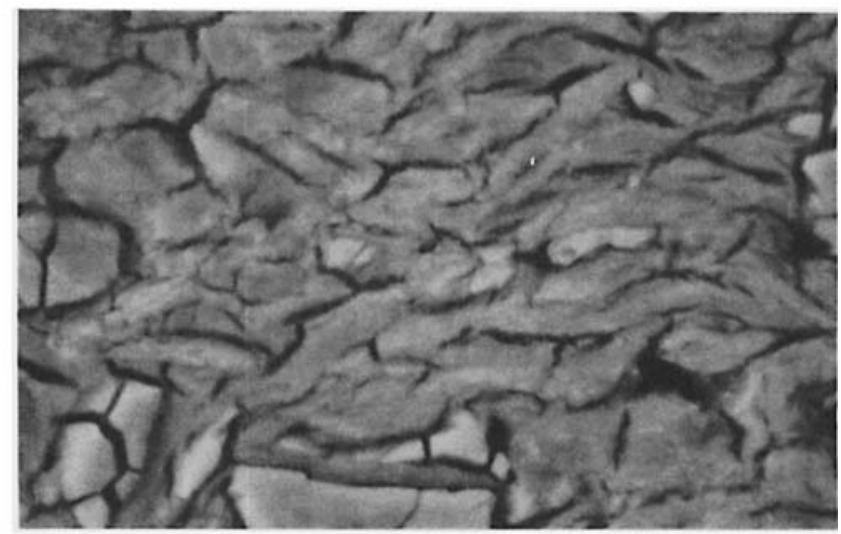

(c)

Fig. 1. (a) An extruded $\mathrm{Bi}_{2} \mathrm{Sr}_{2} \mathrm{CaCl}_{2} \mathrm{O}_{8+\chi}$ rod, which shows zero resistance at $89 \mathrm{~K}$. Its microstructure is also shown by (b) optical microscopy and (c) SEM.

Without heat treatment, the extruded product was superconducting with a transition temperature $T_{\mathrm{c}} \approx 90 \mathrm{~K}$, determined by magnetic susceptibility measurement, as shown in Fig. 3(a). The electrical resistances were measured both parallel and perpendicular to the extrusion direction, as shown in Fig. 3(b), which indicates that the resistance (in the normal state) in the extrusion direction is 4 - to 5-fold lower than that in the perpendicular direction.

\section{(2) Grain Growth of Extruded Y10A}

An extruded rod of the Y10A composite is shown in Fig. 4(a) together with its microstructure before (Fig. 4(b)) and after (Figs. 4(c) and (d)) extrusion. X-ray diffraction analysis of the extruded billet found rather little texture for the tetragonal zirconia phase. A stronger texture, however, was apparent for the alumina phase with its basal plane parallel to the extrusion direction. The main microstructural change found was grain growth. At $1650^{\circ} \mathrm{C}$ and without strain the grain size at the end of the billet grew from its initial $0.35 \mu \mathrm{m}$ to about $1.2 \mu \mathrm{m}$ within $100 \mathrm{~min}$, before entering the deformation zone. The grain growth behavior can be approximately described by the relation $d=d_{0}(1+a t)^{1 / 3}$, where the constant $a \approx$ $0.006 \mathrm{~s}^{-1}$. Since the flow stress is very sensitive to the grain size, the grain growth will influence the extrusion behavior, as will be discussed later. Comparing the microstructure of the billet end and the extruded section, both held at $1650^{\circ} \mathrm{C}$ for the same time, we found relatively similar microstructures, indicating that under the present deformation condition the dynamic grain growth of this material seemed insignificant.

\section{(3) Friction Coefficient and Its Effect on Ram Pressure}

The friction coefficient $\mu$ can be determined by Eqs. (1) and (4). The ram pressure is higher than the die inlet pressure by a factor $\exp \left(4 \mu L / D_{\mathrm{i}}\right)$, so that $\mu=\left(D_{\mathrm{i}} / 4\right)(\partial(\ln P) / \partial L)$, wherc $L$ is the length of the remaining billet before entering the die inlet. Thus, as extrusion proceeds and the length of the billet is reduced, the ram pressure should decrease exponentially. An example of such an exponential decay from the experiment on $\mathrm{Bi}_{2} \mathrm{Sr}_{2} \mathrm{CaCu}_{2} \mathrm{O}_{8+X}$ is shown in Fig. 5(a). The small oscillation in the load was probably due to various stickand-slide frictional events which may occur when the normal pressure is high. By fitting the measured load and displacement data, the friction coefficient was estimated to be 0.08 (for a graphite-silver jacket).

When a jump in ram velocity from $V_{\mathrm{i} 1}$ to $V_{\mathrm{i} 2}$ occurs, the inlet pressure, or extrusion stress $\left(\sigma_{\mathrm{i}}\right)$ should increase if the material flow stress is rate sensitive. The ram pressure increase can be used to estimate rate sensitivity, since $\sigma_{\mathrm{i} 2}: \sigma_{\mathrm{i} 1}=$ $P_{2}: P_{1}=\left(V_{\mathrm{i} 2} / V_{\mathrm{i} 1}\right)^{m}$. After the jump, the normal decay resumes according to Eq. (4). An example of such repeated load jumps and decays from one of our experiments is shown in Fig. 5(b).

\section{(4) Effect of Extrusion Speed and Temperature}

Knowing the friction coefficient and the length of the billet at all times and using Eq. (4), the data for ram pressures $P$ can be converted to the extrusion stresses $\left(\sigma_{\mathrm{i}}\right)$ for those speeds. This procedure is followed to obtain the extrusion stress reported below. The data of $\mathrm{Bi}_{2} \mathrm{Sr}_{2} \mathrm{CaCu}_{2} \mathrm{O}_{8+X}$ are shown for illustration.

In Fig. 6(a) we find that when the ram speed increased by 2 orders of magnitude, the load increased by a factor of 3.5 . According to the analysis of Section II, this dependence is attributed to a strain rate sensitivity in the creep law, $m=$ $\partial\left(\ln \sigma_{\mathrm{i}}\right) / \partial\left(\ln V_{\mathrm{i}}\right)$. When all the extrusion data were analyzed 


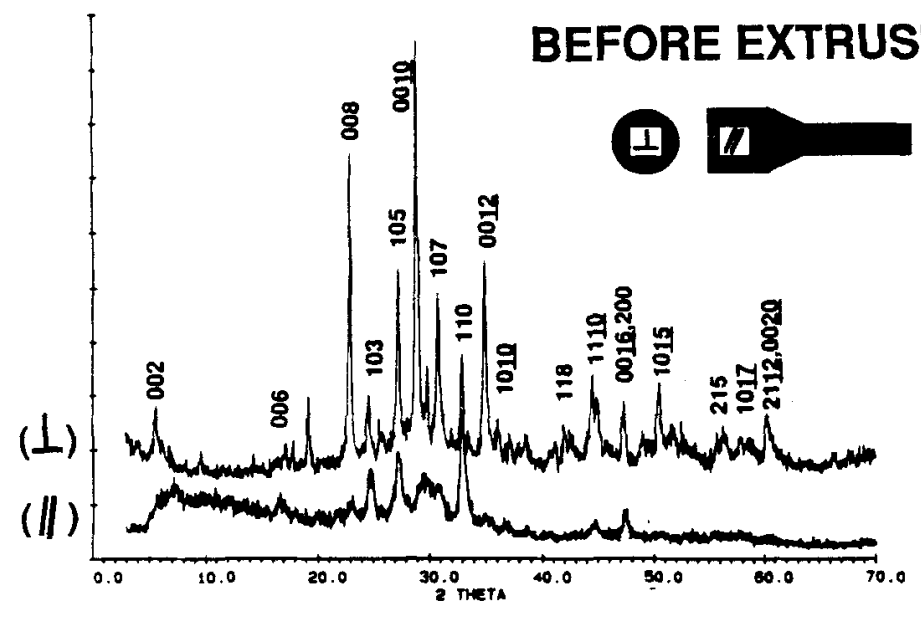

AFTER EXTRUSION

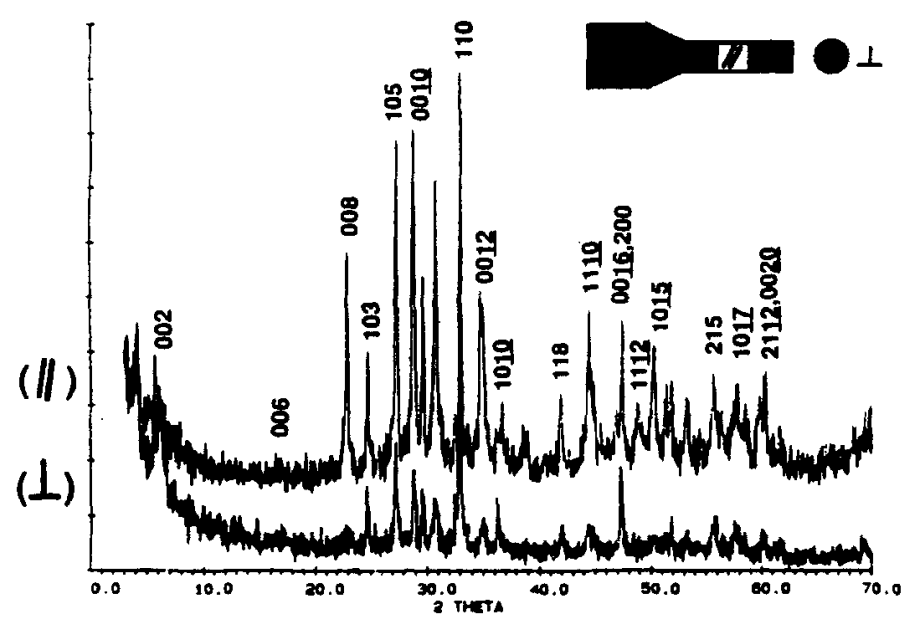

Fig. 2. X-ray diffraction patterns of the hot-pressed billet and the same after extrusion. Here "//" and " $\perp$ " refer to the surfaces sectioned parallel and perpendicular to the extrusion direction.

in this way, an average strain rate sensitivity of 0.27 was obtained.

The temperature dependence of the extrusion load was also investigated, as shown in Fig. 6(b). The extrusion load at a constant ram speed decreases with increasing temperature. An Arrhenius plot of the ram speed at a constant load against reciprocal absolute temperature is shown in Fig. 7. The average activation energy $Q$, obtained from the best fit of the experimental data into Eq. (2), is $1090 \mathrm{~kJ} / \mathrm{mol}$ or $11.3 \mathrm{eV}$.

In the above figures, the model predictions on the extrusion pressures have also been shown. In this calculation the material parameters $m, Q$ and $k_{0}$ were derived from best-fitting of all of the experimental data $\left(k_{0}=5.9 \times 10^{-13} \mathrm{MPa} \cdot \mathrm{s}^{m}, m=\right.$ 0.27 , and $Q=1090 \mathrm{~kJ} / \mathrm{mol}$ ). The apparently satisfactory fit indicates that the constitutive equation for flow stress, with $k=k_{0} \exp (m Q / R T)$, is an adequate one.

\section{(5) Effects of Die Angle and Extrusion Ratio}

The effect of die angle is shown in Fig. 8(a). Also shown are the model predictions. As can be seen within the range tested, the extrusion load at a constant ram speed increases monotonically with the die angle, and within the die angle range studied, $30^{\circ}$ has the lowest extrusion pressure. It is notable that for extrusion of a rate-independent material (such as many metals at lower temperatures and higher speeds) an intermediate die angle around $60^{\circ}$ usually has the lowest extrusion pressure or the best extrusion efficiency. This is obviously not the case for the present rate-sensitive material at the extrusion speed studied.

The effect of the extrusion ratio is shown in Fig. 8(b). The extrusion load at a constant ram speed increases monotonically with the extrusion ratio. This is expected from both the rateindependent and the rate-dependent models.

In the above figure, we have again included the model predictions for the angle and extrusion ratio dependences. Although the model predicts the general trend of these effects, a close agreement seems lacking. This is possibly related to the complex texture effect on the material flow behaviors and the variation of the friction. However, if all the measured extrusion stresses are plotted against the model predictions, as shown in Fig. 9, a tolerably good agreement appears to obtain over a variety of extrusion conditions. This final comparison lends some credence to the extrusion model described in Section II.

\section{(6) Effect of Grain Growth in Y10A}

In Y10A it was found that if extrusion was performed under a constant ram velocity, then the extrusion load would increase monotonically because of static grain growth. On the other hand, if the extrusion was under a constant ram pressure of $32 \mathrm{MPa}$ (the safe operation upper limit for graphite tools), then the extrusion speed would be too slow, at below $1600^{\circ} \mathrm{C}$, to complete a run within several hours. An optimum condition was found to be at $1650^{\circ} \mathrm{C}$, at which this material can be extruded within $2 \mathrm{~h}$ for different die angles. 


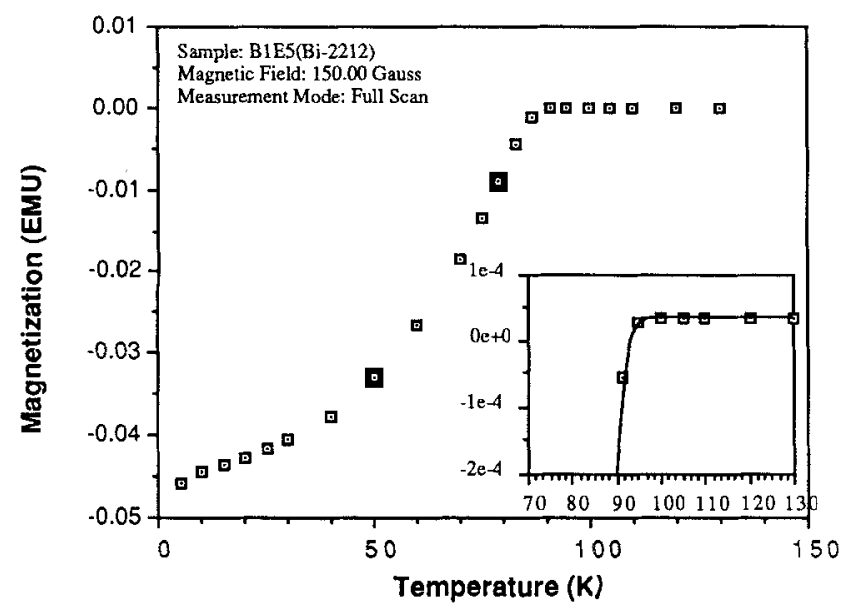

(a)

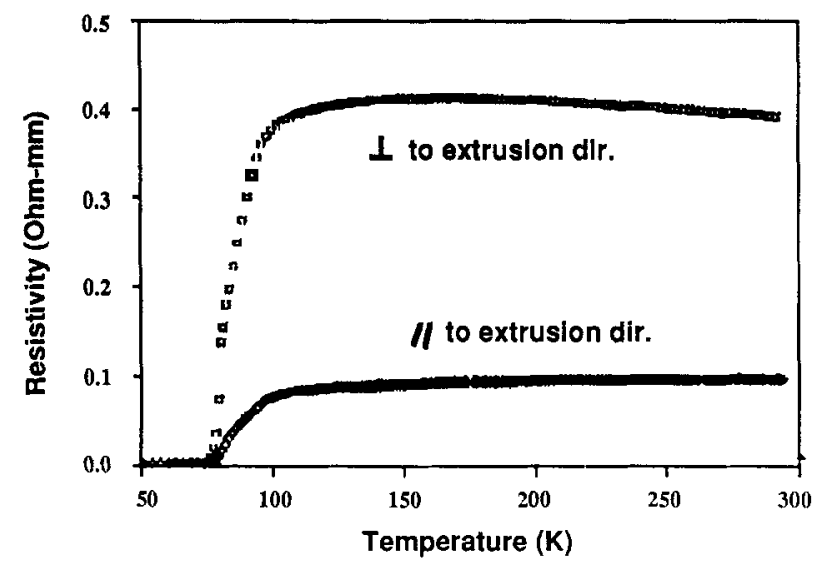

(b)

Fig. 3. (a) Magnetic susceptibility and electrical resistivity vs temperature of an extruded $\mathrm{Bi}_{2} \mathrm{Sr}_{2} \mathrm{CaCu}_{2} \mathrm{O}_{8+X}$ rod. Resistivity measured along and perpendicular to the extrusion axis.
Figure 10 shows the extrusion ram displacement versus time for three die angles, $30^{\circ}, 45^{\circ}$, and $60^{\circ}$, at the extrusion temperature of $1650^{\circ} \mathrm{C}$. Also shown in the figure are calculated curves of displacement versus time for the same condition, where the static grain growth law was fitted as $d=d_{0}(1+0.006 t)^{1 / 3}$ ( $t$ is the extrusion time in seconds), and the dynamic grain growth was not considered. In examination of these data, we are reminded that, under constant ram pressure condition, the extrusion speed is expected to accelerate as extrusion proceeds, because of the decreasing billet length that decreases friction. It can be seen in Fig. 10, however, that only for the $30^{\circ}$ die can we detect some speed acceleration while in all others the effect of grain growth is so dominant that the flow stress continues to increase, rendering extrusion more difficult and the extrusion speed lower. (The $30^{\circ}$ die extrusion was the fastest and thus least subject to static grain growth.) These different behaviors have been correctly predicted by our extrusion model.

\section{Discussion}

\section{(1) Validity of the Extrusion Model}

Although we have not described the detailed development or our extrusion model, it suffices to mention that it is based on the slab analysis of Sachs ${ }^{17}$ and the upper bound analysis of Hosford, ${ }^{18}$ extended to the rate-sensitive conditions characteristic of hot extrusion of ceramics at moderate extrusion speed. (A similar analysis for rate-sensitive materials was recently given by Kellett ${ }^{22}$ using a flow field different from that of the slab method, but yielding predictions very similar to ours.) This analysis is probably reasonably accurate at the intermediate die angle, say between $30^{\circ}$ and $60^{\circ} \mathrm{C}$, which essentially covers the range of practical interest. At lower angles the frictional contribution is dominant and some discrepancy between prediction and data is not unexpected. At high angles, our upper-bound treatment of the redundant work is an overestimation and the error is probably significant enough to render the predicted extrusion pressure inaccurate. In examination of the data in Fig. 8 we did notice a certain discrepancy at $30^{\circ}$ and a diverging trend at $60^{\circ} \mathrm{C}$ and beyond.

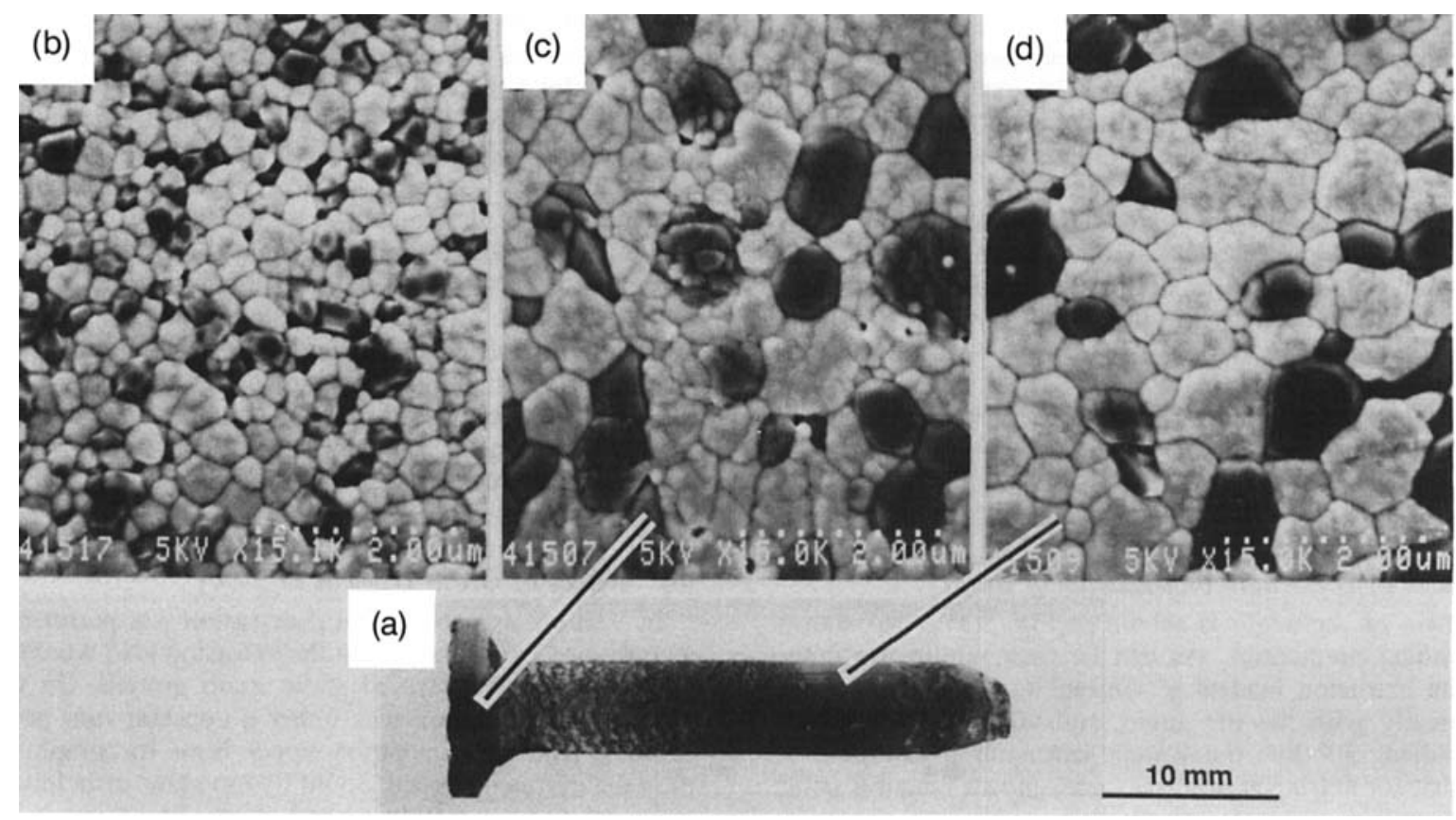

Fig. 4. (a) $\mathrm{A} 2 \mathrm{Y}$-TZP:10\% $\mathrm{Al}_{2} \mathrm{O}_{3}$ specimen extruded at $1650^{\circ} \mathrm{C}$ for $100 \mathrm{~min}$. Also shown are microstructures of (b) a hot-pressed billet, (c) an undeformed billet held at the extrusion temperature, and (d) an extruded billet. 


\section{(2) Constitutive Equation of Hot Deformation}

The determination of material parameters $k, Q$, and $m$ from extrusion experiments allows us to predict the creep equation for $\mathrm{Bi}_{2} \mathrm{Sr}_{2} \mathrm{CaCu}_{2} \mathrm{O}_{8+X}$ in the temperature range of $775^{\circ}$ to $825^{\circ} \mathrm{C}$ and the relatively high strain rate range of $10^{-3}$ to $1 \mathrm{~s}^{-1}$. To our knowledge, no creep data in the comparable strain rate and temperature regimes for this material have been reported. However, the strain rate sensitivity of 0.27 and the activation energy of $1090 \mathrm{~kJ} / \mathrm{mol}$ (or $11.3 \mathrm{eV}$ ) seem to be quite reasonable for a power-law creeping ceramic. The activation energy of $1090 \mathrm{~kJ} / \mathrm{mol}$, though very high, is comparable to that found in the other perovskite systems such as $\mathrm{BaTiO}_{3}{ }^{23}$ and $\mathrm{YBa}_{2} \mathrm{Cu}_{3} \mathrm{O}_{x}{ }^{2}$

We suggest that these data are representative of compression along the $c$-axis in view of the texture in the deformation zone. The results obtained in $\mathrm{Bi}_{2} \mathrm{Sr}_{2} \mathrm{CaCu}_{2} \mathrm{O}_{8+X}$ suggest that hot extrusion of solid billets offers a valuable research tool for studying high-temperature deformation of brittle ceramics at relatively high strain rates and large strains. This is due to the presence of a primarily triaxial compressive stress state in the extrusion process, which suppresses crack propagation even at large deformations and relatively high strain rates. Although the deformation field in extrusion is not uniform, it is probably geometrically self-similar at all extrusion speeds when the steady state is reached. Thus, the local strain rate is simply proportional to the extrusion speed so that the overall deformation may be regarded to proceed at a characteristic strain rate dictated by the ram speed only. In principle, therefore, deformation data of brittle ceramics in the intermediate to high strain rate regime can be obtained from extrusion experiments.

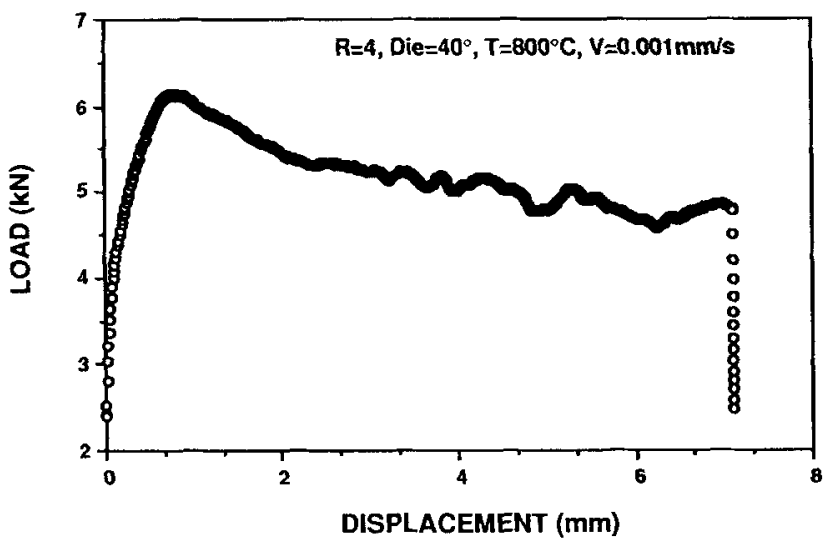

(a)

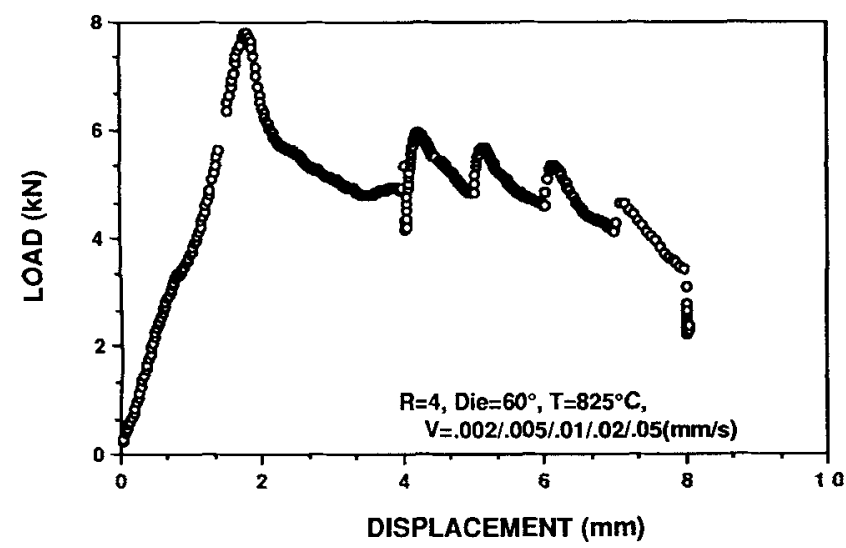

(b)

Fig. 5. Extrusion load vs ram displacement for an experiment with (a) constant speed and (b) several step increases in ram speed.

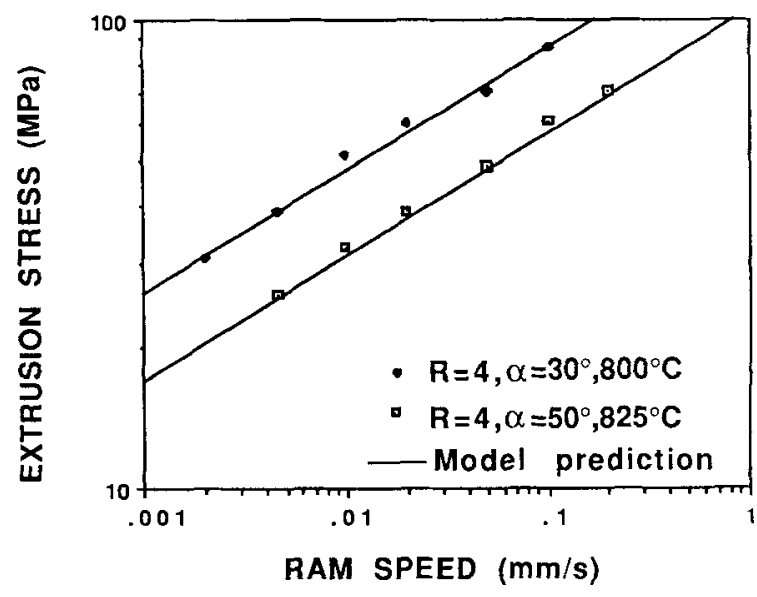

(a)

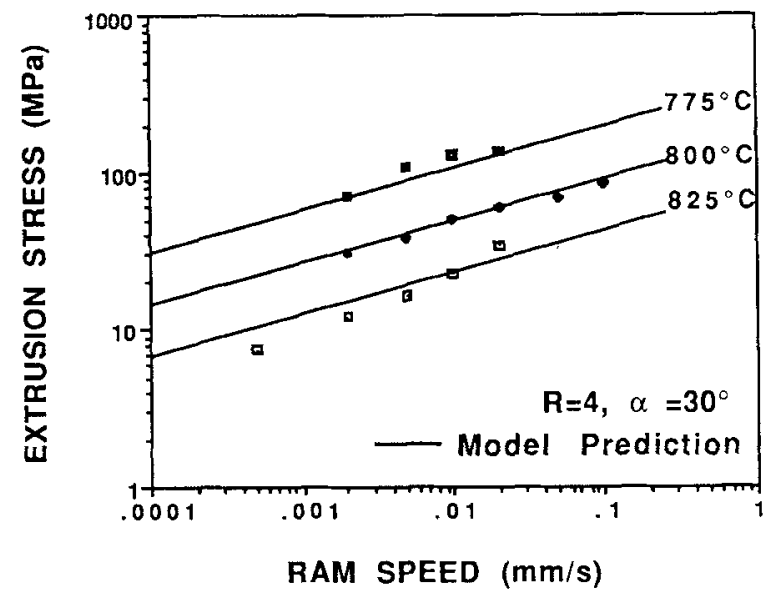

(b)

Fig. 6. Extrusion stress vs (a) ram speed and (b) die angle. Also shown as solid curves are model predictions.

\section{(3) Feasibility of Hot Extrusion of Ceramics}

The extrusion process for ceramics can be limited by the following conditions: (1) the upper-bound ram pressure $P$ limited by the tool strength; (2) the upper-bound stain rate $\dot{\varepsilon}$, limited by the formability or fracture strength of the extrusion

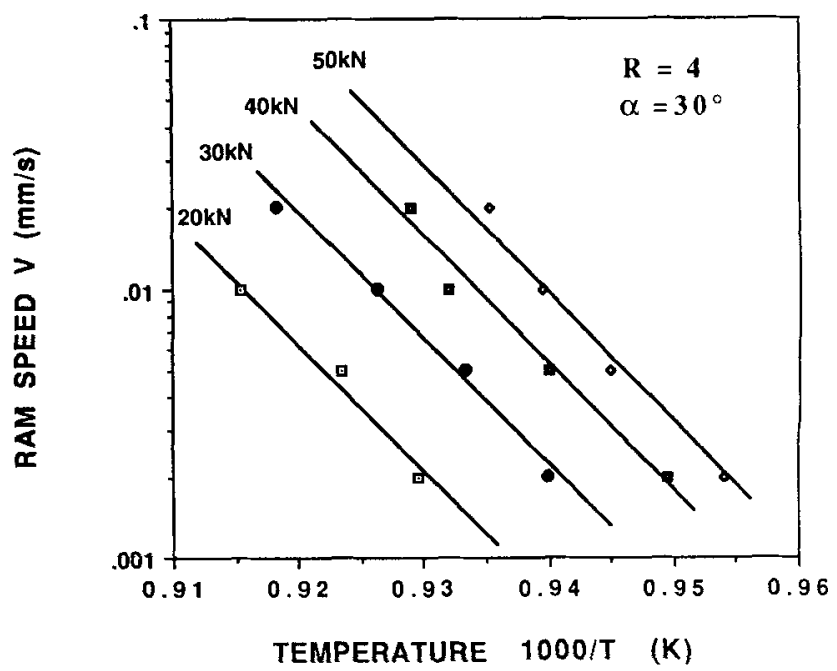

Fig. 7. Extrusion speed vs reciprocal temperature. Also shown as solid lines are model predictions. 


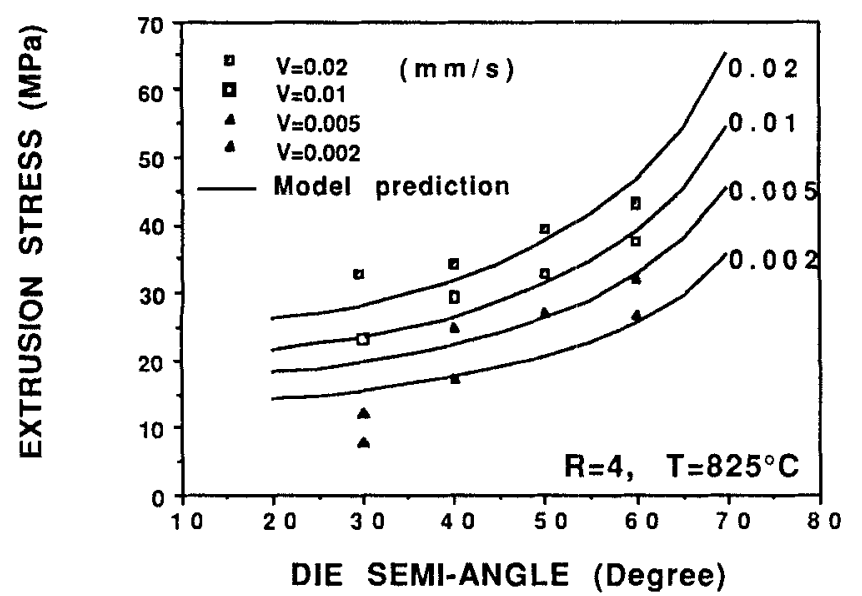

(a)

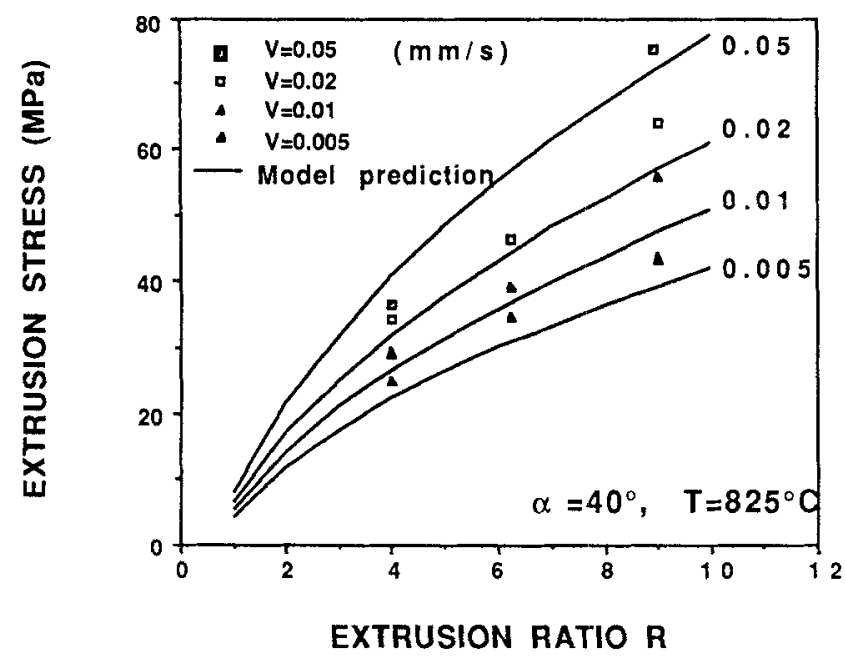

(b)

Fig. 8. Extrusion stress vs (a) die angle and (b) extrusion ratio. Also shown are model predictions.

material; (3) the upper-bound temperature, limited by the material stability, or by the equipment; and (4) the lower-bound outlet velocity $V_{o}$, required by the productivity.

Some useful insight into the extrusion feasibility can now be obtained. We notice from Eq. (4) that the maximum strain rate occurs at the outlet, given by $4\left(V_{\mathrm{o}} / D_{0}\right) \tan (\alpha)$. From condition 4 we may take $V_{\mathrm{o}}=1 \mathrm{~mm} / \mathrm{s}$ as the minimum extrusion speed requirement. Meanwhile we may further take the upper-bound strain rate as $0.1 \mathrm{~s}^{-1}$, noting that most ceramics will probably develop permanent internal cracking at higher rates even in constrained compressive deformation unless they are cxtruded at very high homologous temperatures. By taking $\alpha=30^{\circ}$ we then get an outlet diameter $D_{0}$ larger than $20 \mathrm{~mm}$. This illustrates that for a reasonable extrusion speed, hot extrusion is feasible only for large cross-section products. The inherent limitation here is imposed by the upper-bound strain rate of the ceramics because of concern for brittle fracture.

Extrusion can also be limited by the strength of available high-temperature tooling materials. Typically, calculation along the line of Section II suggests an extrusion stress in the range of 5 to 10 times that of inlet flow stress of the extrusion materials. Structural ceramics have high flow stresses (in excess of $50 \mathrm{MPa}$, for example) at high strain rates $\left(10^{-3}\right.$ to $10^{-1} \mathrm{~s}^{-1}$ ) even at very high temperatures (e.g., $1650^{\circ} \mathrm{C}$ for $\mathrm{Y} 10 \mathrm{~A}$ ). Choosing a tooling material that can withstand such high temperatures and extrusion stresses should prove extremely difficult, yet most critical. For example, while we

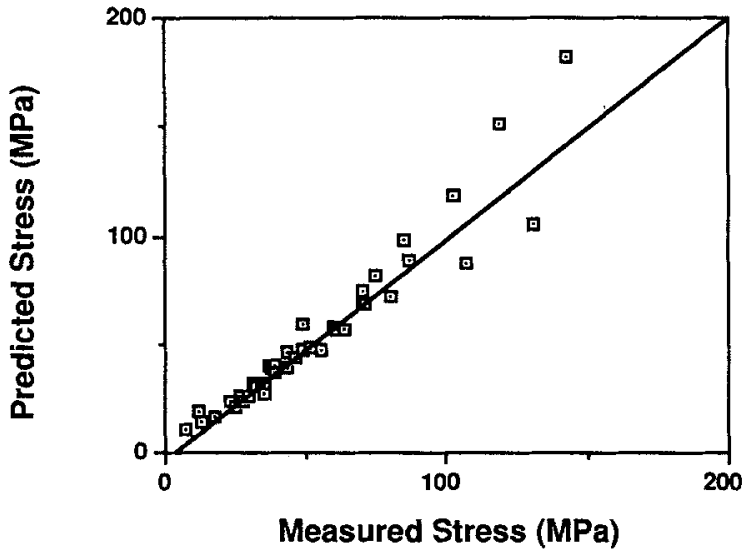

Fig. 9. Comparison of measured extrusion stresses and model predictions for a variety of extrusion conditions.

have used a graphite tool material that has a strength of $50 \mathrm{MPa}$ at the operating temperature of Y10A extrusion, the best state-of-the-art graphite with twice the strength would have allowed extrusion rates several times faster than the one achieved in this study.

\section{Conclusions}

A solid $\mathrm{Bi}_{2} \mathrm{Sr}_{2} \mathrm{CaCu}_{2} \mathrm{O}_{8+X}$ ceramic superconductor and a 2Y-TZP: $10 \mathrm{wt} \% \quad \mathrm{Al}_{2} \mathrm{O}_{3}$ structural ceramic composite have been hot-extruded through conical dies. For $\mathrm{Bi}_{2} \mathrm{Sr}_{2} \mathrm{CaCu}_{2}$ $\mathrm{O}_{8+X}$ the extrusion was performed at temperatures from $775^{\circ}$ to $825^{\circ} \mathrm{C}$, and extrusion speeds from 0.0005 to $0.2 \mathrm{~mm} / \mathrm{s}$, with the die semi-angles ranging from $30^{\circ}$ to $60^{\circ}$ and extrusion ratios from 4 to 9 . The extruded rod is highly textured, superconducting, with a high current-carrying capability along the rod axis as desired. For $2 \mathrm{Y}$-TZP: $10 \% \mathrm{Al}_{2} \mathrm{O}_{3}$ the extrusion conditions were more restricted because of the limitations of the tool strength and the grain growth at high temperatures. An extrusion speed of $0.017 \mathrm{~mm} / \mathrm{s}$ was possible at $1650^{\circ} \mathrm{C}$.

Using an approximate analytical extrusion model for strainrate-sensitive materials, we have analyzed the extrusion stress and verified the extrusion mechanics. The extrusion stress is found to depend on the extrusion ratio and extrusion angle, in addition to extrusion speed. The rate-sensitivity of the material dictates that a smaller die angle, around $30^{\circ} \mathrm{C}$, is most favorable for minimizing the extrusion load. The effect of grain growth

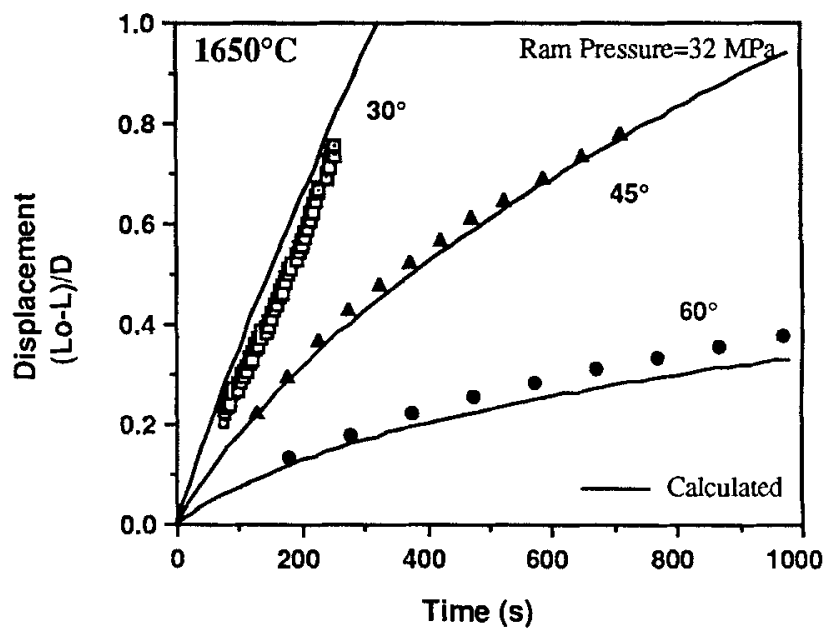

Fig. 10. Displacement vs time from extrusion of $\mathrm{Y} 10 \mathrm{~A}$ at $1650^{\circ} \mathrm{C}$ Also shown are model predictions. 
on extrusion has also been taken into account, and it dominates in the extrusion of $2 \mathrm{Y}-\mathrm{TZP} / \mathrm{Al}_{2} \mathrm{O}_{3}$ ceramics.

The experiments demonstrate that hot extrusion could be a research tool for obtaining material deformation data in the high strain and strain rate regime, for which the conventional tension or compression tests are not feasible. From the obtained experimental data for $\mathrm{Bi}_{2} \mathrm{Sr}_{2} \mathrm{CaCu}_{2} \mathrm{O}_{8+\chi}$, the rate sensitivity and the activation energy have been determined as 0.27 and $1090 \mathrm{~kJ} / \mathrm{mol}(11.3 \mathrm{eV})$, respectively, for strain rates in the range of $10^{-3}$ to $10^{-1} \mathrm{~s}^{-1}$.

Hot extrusion can be a feasible ceramic manufacturing technique if a textured structure is desired. However, its use will probably be limited to large cross-section products of low melting point nonstructural ceramics.

\section{References}

${ }^{i}$ I-W. Chen, X. Wu, S. J. Keating, C. Y. Keating, P. A. Johnson, and T. Y. Tien, "Texture Development in $\mathrm{YBa}_{2} \mathrm{Cu}_{3} \mathrm{O}_{x}$ by Hot Extrusion and HotPressing," J. Am. Ceram. Soc., 70 [12] C-388-C-390 (1987)

${ }^{2}$ P.E. Reyes-Morel, X. Wu, and I-W. Chen, "Deformation Characteristics of Textured $\mathrm{Bi}_{2} \mathrm{Sr}_{1.5} \mathrm{Ca}_{1.5} \mathrm{Cu}_{2} \mathrm{O}_{8+x}$ and $\mathrm{YBa}_{2} \mathrm{Cu}_{3} \mathrm{O}_{6+x}$ Polycrystals"; pp. $590-97$ in Research Update, Ceramic Superconductors II. Edited by M. F. Yan. American Ceramic Society, Westerville, OH, 1988

${ }^{3}$ Y. Yamada, N. Fukushima, S. Nakayama, H. Yoshina, and S. Murase, "Critical Current Density of Wire Type Y-Ba-Cu Oxide Superconductor," Jpn. J. Appl. Phys., 26 [5] L865-66 (1987).

${ }^{4} \mathrm{~S}$. Jin, R. C. Sherwood, R. B. VanDover, T.H. Tiefel, and D. W. Johnson, Jr., "High $T_{\mathrm{c}}$ Superconductors-Composite Wire Fabrication," Appll. Phys. Lett., 51, 203 (1987).

${ }^{5} \mathrm{O}$. Kohno, Y. Ikeno, N. Sadakata, and K. Goto, "High Critical Current Density of Y-Ba-Cu Oxide Wire without a Metal Sheath," Jpn. J. Appl. Phys., 27 (1) L77-79 (1988)

"N. Sadakata, Y. Ikeno, M. Nakagawa, K. Gotoh, and O. Kohno, "Fabrication and Superconducting Properties of High $T_{c}$ Oxide Wire," Mater. Res. Soc. Symp. Proc., 99, 293-96 (1988).

${ }^{7}$ K. Togano, H. Kumakura, and H. Shimizu, "Developments of Tape and Wire Fabrication Processes for High $T_{\mathrm{c}} \mathrm{Ba}_{2} \mathrm{YCu}_{3} \mathrm{O}_{7-x}$ Oxide Superconductors," Mater. Res. Soc. Symp. Proc., 99, 191-96 (1988).
${ }^{*}$ K. C. Goretta, A. J. Schultz, D. W. Capone II, T. L. Tolt, U. Balachadran, J. T. Dusek, M. T. Lanagan, R. B. Poeppel, J. P. Singh, D. Shi, R. L. McDaniel, D. S. Applegate, J. K. Degener, and J.S. Kallend, "Texturing of $\mathrm{RBa}_{2} \mathrm{Cu}_{3} \mathrm{O}_{x} \mathrm{Su}$ perconductors"; pp. 323-31 in Research Update, Ceramic Superconductors 11 Edited by M. F. Yan. American Ceramic Society, Westerville, OH, 1988.

${ }^{9}$ T. H. Tiefel, S. Jin, R. C. Sherwood, R. B. Van Dover, R. A. Fastnacht, M. E. Vavis, D. W. Johnson, and W.W. Rhodes, "Fabrication and Properties of High- $T_{\mathrm{c}}$ Superconducting Wires," J. Appl. Phys., 64 [10] 5890-901 (1988).

${ }^{10} \mathrm{~T}$. Hikata, K.-I. Sato, and H. Hitotsuyanagi, "Ag-Sheathed Bi-Pb-Sr-CaCu-O Superconducting Wires with High Critical Current Density,"Jpn. J. Appi. Phys., 28 [1] L77-79 (1988).

${ }^{11}$ I.-G. Chen, S. Sen, C. H. Chen, and D. M. Stefanescu, "Fabricating $\mathrm{Ag}_{2} \mathrm{O}$ Stabilized Superconductive Wires," J. Met., 41 [4] 31-33 (1989).

${ }^{12}$ K. Rajan, R. M. German, D. B. Knorr, R. K. MacCrone, W. Misiolek, and R. N. Wright, "Deformation Processing of High- $T_{\mathrm{c}}$ Superconducting Oxides," J. Met., 41 [4] 28-30 (1989).

${ }^{13}$ R. B. Poeppel, S. E. Dorris, C. A. Youngdahl, J. P. Singh, and M. T. Lanagan, "Shape Forming of High $T_{\mathrm{c}}$ Superconductors," $J$. Met., 41 [1] 11-13 (1989).

${ }^{14} \mathrm{C}$. Carry and A. Mocellin, "Examples of Superplastic Forming FineGrained $\mathrm{Al}_{2} \mathrm{O}_{3}$ and $\mathrm{ZrO}_{2}$ Ceramics"; pp. $1043-52$ in Materials Science Monographs, Vol. 38A, High Tech Ceramics. Edited by P. Vincenzini. Elsevier Science Publishers, Amsterdam, Netherlands, 1987.

${ }^{15}$ B. J. Kellett, C. Carry, and A. Mocellin, "High Temperature Extrusion Behavior of a Superplastic-based Ceramic," J. Am. Ceram. Soc., 73 [7] 1922-27 (1990).

${ }^{16}$ I-W. Chen and L. A. Xue, "Development of Superplastic Structural Ceramics," J. Am. Ceram. Soc., 73 [9] 2585-609 (1990).

${ }^{17} \mathrm{O}$. Hoffman and G. Sacks, Introduction to the Theory of Plasticity for Engineers; pp. 176-86. McGraw-Hill, New York, 1953.

${ }^{18}$ W. F. Hosford and R. M. Caddell, Metal Forming, Mechanics and Metallurgy; pp. 143-67. Prentice-Hall, Englewood Cliffs, NJ, 1983.

${ }^{19}$ B. Aritzur, Metal Forming: Processes and Analysis; Chs. 8-10. McGrawHill, New York, 1968.

${ }^{20}$ B. Avitzur, Handbook of Metal-Forming Processes; Chs. 3, 4. WileyInterscience, New York, 1983.

${ }^{21}$ X. Wu, Deformation Processing of Ceramics; Ph.D. Dissertation. University of Michigan, Ann Arbor, MI, 1991.

${ }_{22}$ B. J. Kellett, "High Temperature Extrusion Behavior of Fine-grained $\mathrm{ZrO}_{2}$," J. Mater. Res., 5 [10] 2165-71 (1990).

${ }^{23} \mathrm{C}$. Carry and A. Mocellin, "Superplastic Creep of Fine-Grained $\mathrm{BaTiO}_{3}$ in a Reducing Environment," J. Am. Ceram. Soc., 69 [9] C-215-C-216 (1986). 